\title{
Aletheia: contra el olvido* \\ Estrategias a través del arte para elaborar la memoria emocional ¿Qué hacer con el patrimonio inmaterial del recuerdo traumático?
}

\author{
Aletheia: against oblivion \\ Strategies through art to elaborate emotional memory. \\ What to do with the intangible heritage of the traumatic memory?
}

Marián López Fdz. Cao

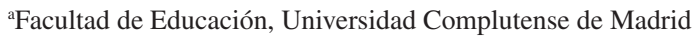

Correo electrónico: mariaanl@ucm.es

\begin{abstract}
RESUMEN
El presente artículo aborda el papel de las artes como agente social que recupera y da forma a la memoria emocional derivada del trauma. El arte es motor de procesos psíquicos que puede ayudar a dar forma al dolor traumático, a la vez que se convierte en agente comunitario que da forma y hace visible la ausencia, la desaparición y el duelo y se convierte en patrimonio inmaterial de un valor indudable. El artículo se centrará en: analizar cómo los procesos creadores pueden ser vehículo de elaboración y restauración, desde un punto de vista psicológico y neurocientífico; documentar el trabajo artístico y visual -en concreto el cómic- en la memoria traumática, surgida de los conflictos interpersonales y sociales, que pueden considerarse como prácticas ejemplificatorias. Finalmente, se esbozará una metodología en educación y terapia para abordar la memoria emocional a través del arte.
\end{abstract}

Palabras clave: memoria, trauma, patrimonio, educación, arte, imagen.

\begin{abstract}
The article will address the role of arts as a social agent that recovers and forms the emotional memory derived from trauma. Art is a motor of psychic processes that can help shaping traumatic pain, while becoming a community agent that gives form and makes visible the absence, disappearance and mourning and becomes intangible heritage of undoubted value. The article will focus on: analyzing how creative processes can be a vehicle for elaboration and restoration, from a psychological and neuroscientific point of view; addressing artistic and visual work -specially comic strip- in the traumatic memory, arising from interpersonal and social conflicts, which can be considered as exemplifying practices. Finally, a methodology will be outlined in education and therapy to deal with emotional memory through art.
\end{abstract}

Keywords: memory, trauma, heritage, education, art, image.

\footnotetext{
Investigación financiada por el Ministerio de Economía y Competitividad "Aletheia: artes, arteterapia, trauma y memoria emocional", HAR2015-69115.
} 
Estudios Pedagógicos XLIII, N 4: 147-160, 2017

ALETHEIA: CONTRA EL OLVIDO. ESTRATEGIAS A TRAVÉS DEL ARTE PARA ELABORAR LA MEMORIA

EMOCIONAL ¿QUÉ HACER CON EL PATRIMONIO INMATERIAL DEL RECUERDO TRAUMÁTICO?

\section{EL TRAUMA: AQUEL QUE NOS DESPIERTA ENTRADA LA NOCHE}

"Usamos nuestras mentes no para descubrir hechos, sino para ocultarlos"

Antonio Damasio (1999, p. 28)

La memoria emocional configura nuestra existencia desde que nos asomamos a la vida. El cuidado y el vínculo recibido -o ausente- marca de modo indeleble nuestra visión del mundo, la percepción de nosotros mismos y de los otros. La memoria de todo ello, inscrita en nuestros cuerpos de múltiples modos, nos hace sentirnos seguros o inquietos en el mundo y la vida cotidiana; favorece o dificulta nuestra capacidad de atrevernos a pensar y relacionarnos. Cuando esta memoria es traumática, el cuerpo es marcado por una huella profunda de difícil integración.

\subsection{DEFINICIÓN}

El trauma es, por definición, como señala el especialista Van der Kolk (2015), insoportable e intolerable. El común denominador del trauma psicológico, de acuerdo con el Comprehensive Textbook of Psychiatry (2000), es el sentimiento de miedo intenso, fragilidad, pérdida de control y amenaza de aniquilación. En este sentido, el trauma es extraordinario, no porque ocurra raramente, sino porque sobrepasa la normal capacidad de adaptación a la vida. El ser humano queda abocado a un sentimiento sin lenguaje, pre-verbal. Su cuerpo hace síntoma, revive el terror, la rabia o la impotencia, así como desencadena el impulso de lucha o huida, de acción o paralización, en modos y sentimientos imposibles de comprender y difíciles de articular (Van Der Kolk, 2015). Su cuerpo llevará la cuenta -como el título de la obra de Van der Kolk- probablemente, el resto de su existencia.

El trauma psicológico es pues una aflicción definida por la falta de control sobre la situación, a través de una carencia absoluta de poder sobre las circunstancias que le rodean. En el momento del trauma, la víctima se encuentra absolutamente vulnerable en poder de una fuerza que le sobrepasa. Cuando esta fuerza es natural, hablamos de desastres. Cuando la fuerza la llevan a cabo otros seres humanos, hablamos de atrocidades. Los eventos traumáticos sobrepasan los sistemas normales de cuidado que son los que ofrecen a las personas sentimientos de control, vínculo y significado vital.

El reconocimiento del trauma y su tratamiento desde las instituciones médicas y psicológicas es algo bastante reciente. La respuesta común a las atrocidades es hacer que desaparezcan de nuestra conciencia, a costa de lo que sea-aun de nuestra propia estabilidad emocional-. Ciertas violaciones perpetradas en y por la sociedad son demasiado terribles como para pronunciarlas en voz alta: ese es el significado de la palabra "impronunciable". Las atrocidades, sin embargo, como la historia y la psicología nos han enseñado, se niegan a ser enterradas (Herman, 1992).

Desde que la Asociación Americana de Psiquiatría aceptó el trastorno por estrés postraumático (TEPT), en 1980, gracias a la movilización y apoyo de los veteranos norteamericanos provenientes de la guerra de Vietnam, poco a poco se ha ido aceptando y estudiando los mecanismos a través de los cuales el ser humano afronta la atrocidad que ha vivido o visto, en muchos casos negándola, disociándola, reprimiéndola, y cómo esta aparece de modo intrusivo en su vida psíquica, marca su cuerpo y relaciones con los otros, impidiéndole llevar una vida feliz. 
De acuerdo con diversos autores y especialistas (Herman, 1992; Van der Kolk, 1994) podemos afirmar que el estudio sistemático del trauma depende del apoyo de la sociedad donde nace y las correspondientes instancias institucionales y políticas. El estudio del trauma derivado de la confrontación bélica solamente se convierte en estudio posible cuando existe un contexto que legitima y escucha a ese dolor. El estudio del trauma sexual producido en la vida privada solo se convierte en legítimo cuando existe un contexto que se opone y desafía a la subordinación de mujeres y niños en este ámbito y en la sociedad. De este modo y de acuerdo con Herman (1992), únicamente aparecen avances cuando existe un movimiento social -y legal- suficientemente fuerte para legitimar y dar acogida a la alianza entre investigadores y pacientes que contrarresten los procesos comunes de silencio y negación. La represión, la disociación y la negación son fenómenos que ocurren tanto en la conciencia individual como en la conciencia social (Herman, 1992).

\subsection{LOS EFECTOS EN LA FRAGILIDAD DEL SER}

En el trastorno de estrés postraumático, el trauma afecta a todo nuestro ser: a nuestro cuerpo, a nuestra mente y nuestro cerebro. De algún modo, mucho después de que el evento concreto haya pasado, el cuerpo sigue defendiéndose de una amenaza que pertenece al pasado: a través de las glándulas adrenales y las hormonas del estrés, a partir del tracto digestivo, ralentizando o colapsando las vísceras; a través del sistema cardiovascular, potenciando una mayor aceleración del pulso, aumentando el oxígeno para una posible lucha o huida; a través de la glándula tiroidea, etc. Todo el cuerpo continúa alerta, años después de que el peligro haya pasado, sin poder acceder a una capacidad -situada en el neocortex- que valore ese desencadenamiento de estrés y vulnerabilidad:

Las señales de peligro de la amígdala desencadenan la liberación de potentes hormonas del estrés, como cortisol y adrenalina, que hacen aumentar el ritmo cardíaco, la presión sanguínea y el ritmo de la respiración, preparándonos para luchar o escapar. Una vez que el peligro ha pasado, el cuerpo vuelve a su estado normal bastante rápidamente. Pero cuando la recuperación se bloquea, el cuerpo se ve llamado a defenderse, haciendo que la gente se sienta agitada y excitada [...]. En el TEPT, el equilibrio crítico entre la amígdala y la corteza pre-frontal media cambia radicalmente, complicando el control de las emociones y los impulsos. (Van der Kolk, 2015, p. 68).

Por otro lado, como señala Van der Kolk, y apelando a la neuroplasticidad del cerebro, el sistema límbico, responsable junto con el cerebro reptiliano del llamado cerebro emocional, se conforma a través de la experiencia (Van der Kolk, 2015). Si nos sentimos seguros y amados, nuestro cerebro se especializa en la exploración, el juego y la cooperación. Si nos sentimos atemorizados y no deseados, se especializa en el manejo de los sentimientos de miedo y abandono (Van der Kolk, 2015). Cuando el trauma se produce a edades tempranas, y en el entorno familiar -en una cautividad de la cual la persona no puede ni sabe escapar o hacer frente- las conductas desadaptativas se agravan de modo a veces irremediable. Las teorías del apego, desarrolladas por Ainsworth (1989), Bowlby (1989), Balint (2001, 2006) y Stern (1985), señalan cómo el ser humano crece en relación, en especial, marcada por la relación de los adultos que les cuidan. Gestionar solos el terror produce disociación, adicciones, sensación crónica de pánico y relaciones marcadas por el aislamiento, la desconexión y las explosiones emocionales. 
Estudios Pedagógicos XLIII, N 4: 147-160, 2017

ALETHEIA: CONTRA EL OLVIDO. ESTRATEGIAS A TRAVÉS DEL ARTE PARA ELABORAR LA MEMORIA

EMOCIONAL ¿QUÉ HACER CON EL PATRIMONIO INMATERIAL DEL RECUERDO TRAUMÁTICO?

\section{EL ARTE DE CONTAR. CONTAR CON EL CUERPO}

Según varios autores (Christianson, 1992; Van der Kolk et al., 1994), la memoria implícita y declarativa del evento traumático puede verse desconectada por el impacto del hecho traumático.

Las cualidades del recuerdo traumático se hacen difíciles de describir a través de palabras, o de integrar como parte de la historia de vida. La persona, "atravesada" por el hecho inasumible que ha vivido, es incapaz de construir un relato, o bien lo relata de forma automática (aprendida), sin poder integrarlo somáticamente en su narrativa personal. La dificultad de procesar la información simbólicamente (verbal o de otro modo) tras el trauma es un elemento crucial del Trastorno de Estrés Postraumático (Van der Kolk \& Fisler, 1995). De hecho, investigaciones sobre la imagen cerebral han demostrado baja actividad en el área de Broca, que es la responsable de los aspectos motores del habla, e hiperactividad en la amígdala (miedo, terror), hipocampo (memoria) y corteza occipital (proceso visual) (Rauch \& Shin, 1997).

Lo que está alterado básicamente es la memoria autobiográfica, en tanto que la memoria del trauma no se constituye como una historia coherente donde los aspectos de la experiencia están fusionados en una narrativa y de forma integrada en la dimensión vital e íntima del tiempo subjetivo, sino que las recolecciones del trauma se constituyen en fragmentos separados de la conciencia que no han podido ser integrados y permanecen desconectados de la historia global de la vida de la persona (López Fdz. Cao, 2016). Esta condición fragmentaria implica, en vez de ello, una falta de control de parte de la víctima, que confiere a los recuerdos traumáticos un carácter invasivo e intrusivo que continuará torturando a las víctimas durante un tiempo indefinido. Uno de los objetivos prioritarios de la aproximación terapéutica implica que la víctima intente reconstruir lo que ha sucedido en su experiencia traumática a través de una historia coherente y organizada.

Las memorias traumáticas pueden organizarse y reducir su carga emocional a través de una "narrativa coherente del trauma", que resitúa las memorias traumáticas en memorias declarativas que entonces pueden ser reinterpretadas e integradas en la historia de vida de una persona. Por su naturaleza, las memorias traumáticas son difíciles de expresar solamente a través de palabras (Collie \& Backos, 2006).

Desde 1990, James Pennebaker, un psicólogo social, y sus colegas de investigación (véase, por ejemplo, Francis \& Pennebaker, 1992; Pennebaker \& Beall, 1986) han estado experimentando con el vínculo emocional entre comunicación por escrito y de la salud. La mayoría de los estudios se ha llevado a cabo en condiciones de laboratorio, mediante ensayos controlados aleatoriamente.

Pennebaker (1990) narra la historia de su viaje de investigación desde la inhibición como una amenaza para la salud, y de la escritura (o expresión oral) acerca de las emociones y pensamientos como una forma poderosa de "confesión". El paradigma de Pennebaker no solo ha sido asumido por muchas poblaciones y continentes, sino que también ha recibido una amplia acogida en los medios, con titulares como "la pluma es más poderosa que la píldora" (Bower, 1999).

\subsection{LOS PROCESOS ARTÍSTICOS, ACTIVADORES DE LA ELABORACIÓN Y LA INTEGRACIÓN DEL} TRAUMA

Desde hace ya algunos años ha aparecido un nuevo paradigma que señala a los procesos creadores como válidos para abordar el trauma. Estamos hablando de la neurociencia. 
Este paradigma (Read Johnson, 1998) señala que los procesos que regulan el arte y, por extensión, las terapias a través del arte, tienen un correlato específico en nuestros cerebros. A partir de Bessel van der Kolk (1994), este paradigma se ha erigido como uno de los más importantes en defender el potencial del arte frente a los procesos traumáticos.

Lusebrink (2004) señala algunas reflexiones sobre cómo los medios artísticos, sean estos a través de la narrativa poética, dramática, musical o visual, activan partes específicas del cerebro y a veces de modo simultáneo, de tal modo que los aspectos perceptivos, sensorio-motrices, de la memoria, cognitivos y emocionales pueden ser abordados de un modo nuevo, produciendo la mejora de los individuos. El arteterapia, como modo de utilizar los procesos artísticos para la mejora de los individuos, al activar zonas del cerebro específicas, puede ser y es, de hecho, una vía de trabajo importante para la mejora del bienestar del ser humano. Siguiendo a este autor podemos ver cómo el uso de las artes influye en las conexiones entre las funciones de los lados derecho e izquierdo del cerebro.

Antonio Damasio en su obra El error de Descartes advierte que necesitamos tanto la inteligencia emocional del hemisferio derecho del cerebro como la inteligencia intelectual (verbal) del hemisferio izquierdo para formar juicios y razonamientos (Riley, 2004). Sin la información emocional que envía señales de aviso o confirmación, que nos recuerdan cómo nos hemos sentido en una situación similar, carecemos de recuerdos intrínsecos para ayudarnos a hacer elecciones correctas. Las emociones, integradas con decisiones del pasado, sean satisfactorias o no, son señales que nos informan sobre cómo proceder o si debemos tener cuidado.

En el trauma, las artes permiten que las imágenes relacionadas con estos episodios, y que se han quedado ancladas en alguna parte del cerebro emocional del sujeto, imposibilitándole en muchos casos la elaboración de los mismos, puedan ir emergiendo gradualmente y experimentar de modo seguro los recuerdos corporales y emocionales y así, puedan ser integrados en el aquí y ahora, de modo que los trazados neuronales kinestésicos y emocionales puedan aprender nuevos modos (Siegel, 1999 Cit. en Riley, 2004).

Así pues, el proceso de exploración simbólica puede activar los niveles más básicos de la jerarquía de los procesos perceptivos, incluyendo la corteza sensorial primaria en sus diferentes modalidades, dado que "los símbolos están sólidamente basados en la percepción en virtud de sus orígenes perceptuales y su naturaleza de recuperación perceptual" (Lusebrik, 2004, p. 131)

El arteterapia, a través de la constante interconexión entre hemisferios, entre emoción y cognición, entre imagen y palabra, entre sensación, emoción e intelecto, implicando al ser como un todo donde el cuerpo es mente y la mente cuerpo, es un campo más que favorable para una intervención que implique el desarrollo del ser humano en su totalidad, especialmente allí donde el cuerpo ha quedado atrapado por memorias emocionales o representaciones visuales e imágenes sin elaborar.

\subsection{CONTAR PARA ENTENDER/SE E INTEGRAR EL DOLOR}

Son muchos las y los creadores que han utilizado el proceso creador para entrar en el trauma, desestructurar las imágenes, emociones y acciones que habían quedado congeladas y volvían una y otra vez a la memoria emocional del sujeto, y posteriormente, ayudados por la poesía, la lírica y las artes visuales, volver a organizar ese relato de sufrimiento para que tuviera sentido. Articular de algún modo un procesamiento de un duelo para 
poder constituir, como nos muestran algunos casos, una oportunidad de reposicionamiento subjetivo.

Dentro de la investigación que estamos llevando a cabo en la Universidad Complutense, Aletheia ${ }^{1}$, un I+D financiado por la Universidad Complutense, hemos realizado un proceso de archivo y documentación de procesos creadores que han permitido la afloración de un dolor organizado y asumible por el sujeto, que le permita no solamente seguir viviendo, sino volver a sentir placer por la vida y la relación con los otros.

Valga la visualización de la reciente película Manchester by the sea, de Kenneth Lonergan, que hemos tenido la ocasión de ver en 2017. El sufrimiento del protagonista no se alivia con nada. No hay perdón ni castigo que logren cambiar su terrible soledad y aislamiento. Lee Chandler (Casey Affleck) es un hombre cercano a los cuarenta que trabaja realizando tareas de mantenimiento en Boston: arregla duchas, grifos atascados, saca la basura o vacía de nieve las entradas de los portales. Es de pocas palabras y se mantiene distante de cualquier contacto social. Por las noches sume sus penas en alcohol, y si alguien le mira mal, toda la ira contenida sale de repente. El director es capaz de reconstruir, como en muy pocas películas, las consecuencias del trauma: disociación, flashbacks, recuerdos intrusivos culpabilizadores, lacerantes e insoportables que destruyen y ponen al protagonista al borde de la aniquilación de los otros y de sí mismo; imposibilidad de reconstrucción de los propios hechos, incapacidad para el afecto, atravesamiento de un dolor insoportable y como solución, un ser que bloquea y blinda en la insoportable vida cotidiana, repetitiva y monótona su capacidad de volver a amar y relacionarse con los otros. Simplemente, no puede.

Los procesos que implican organización temporal, como la escritura, el cómic, el teatro, son especialmente reveladores y relevadores de experiencias donde el dolor puede ser contado, estructurado, para comenzar a ser primero soportado y luego, integrado. Además, la representación de caracteres y vivencias provocan empatía en los otros, algo esencial para el vínculo social y la interacción con los otros, que permiten la relación con la sociedad -ser escuchado-, aspecto fundamental en los procesos de duelo al provocar la interacción. La teoría de la mente (ToM, en inglés) puede ayudarnos a comprender la capacidad cognitiva del ser humano de atribuir estados mentales tanto a uno mismo como a los otros (Goldman, 2012). Al añadir acción, intención y conciencia emocional al carácter representado (o al narrador que cuenta su proceso), la Teoría de la Mente prueba lo importante que resulta para la elaboración traumática, la inmersión del lector o lectora en una narración diegética, aunque cercana a la narración de hechos y la construcción plausible.

En la escritura poética emana la narración transida por el afecto y la emoción y se reconstruye de modo simbólico un reposicionamiento ante la pérdida. Los tres textos que presentamos son un ejemplo de ello. Los tres no parecen buscar otro objetivo más que la expresión del dolor - ¿llegar a entendernos en él?-y, a través de ella, integrarlo en una vida que parece detenerse:

Durante las noches azules uno piensa que el día no se va a acabar nunca. A medida que las noches azules se acercan a su fin (y lo hacen, lo hacen siempre) uno experimenta un escalofrío literal, una visión de enfermedad, en el mismo momento de darse cuenta: la luz azul se está yendo, los días ya se están acortando, el verano se ha ido. Este libro se titula "Noches azules" porque en la época en que lo empecé a escribir sorprendí a mi

ALETHEIA. Arte, arteterapia, trauma y memoria emocional. HAR2015-69115-R. https://www.ucm.es/aletheia 
mente volviéndose cada vez más hacia la enfermedad, hacia la muerte de las promesas, el acortamiento de los días, lo inevitable del apagamiento, la muerte de la luz. Las noches azules son lo contrario de la muerte de la luz, pero al mismo tiempo son su premonición. (Didion, 2012, pp. 9-10).

Así relata Joan Didion en su obra Noches azules, los días que siguen a la muerte de su hija: "Es horrible verse morir sin hijos. Lo dijo Napoleón Bonaparte. ¿Puede haber para un mortal un dolor mayor que ver a sus hijos muertos? Lo dijo Eurípides. Cuando hablamos de mortalidad, estamos hablando de nuestros hijos. Eso lo dije yo" (2012, p. 17) señala la autora en su obra, donde describe la relación que mantuvo con su hija Quintana desde que su marido y ella la adoptaran siendo un bebé hasta el fallecimiento de esta con 39 años:

Cuando empecé a escribir estas páginas, yo creía que iban a tratar de los hijos, de los que tenemos y de los que desearíamos tener, de las formas en que dependemos del hecho de que nuestros hijos dependan de nosotros, de las formas en que los animamos a que sigan siendo niños, de las formas en que ellos siempre nos resultan más desconocidos para nosotros que para sus conocidos más casuales; de las formas en que nosotros somos igualmente opacos para ellos. De las formas en que, por ejemplo, escribimos novelas solo para "enseñárnoslas" entre nosotros. (2012, p. 47).

En España, Sergio del Molino, que negó hacer una terapia con su libro, La hora violeta, comienza así su obra:

Este libro es un diccionario de una sola entrada, la búsqueda de una palabra que no existe en mi idioma: la que nombra a los padres que han visto morir a sus hijos. Los hijos que se quedan sin padres son huérfanos, y los cónyuges que cierran los ojos del cadáver de su pareja son viudos. Pero los padres que firmamos los papeles de los funerales de nuestros hijos no tenemos nombre ni estado civil. Somos padres por siempre. Padres de un fantasma que no crece, que no se hace mayor, al que nunca vamos a recoger al colegio, que no conocerá jamás a una chica, que no irá a la universidad y no se marchará de casa. Un hijo que no nos dará un disgusto y a quien nunca tendremos que abroncar. Un hijo que jamás leerá los libros que le dedicamos.

Que nadie haya inventado una palabra para nombrarnos nos condena a vivir siempre en una hora violeta. Nuestros relojes no están parados, pero marcan la misma hora una y otra vez. (Del Molino, 2017, p. 11).

Francisco Umbral, en Mortal y Rosa, relata la tristeza inabordable de la pérdida implacable de su hijo "Cuando me arranco al bosque de los sueños, a la selva oscura del dormir, y me cobro a mí mismo, me voy lentamente completando. Porque he dejado de interesarme por mis sueños. A la mierda con Freud" (Umbral, 2015, p. 17).

Umbral evoca la muerte de su hijo. Desde que es consciente del advenimiento de su muerte, el escritor procura la evocación, y cada sensación es un continuo superar la existencia sin el futuro del amado:

Me arranco, pues, de la selva pantanosa de los sueños y me resumo como puedo, recojo porciones de realidad que yacen tristes por la habitación, me doblo por la mitad y mis 
riñones, cargados de pasado y de licores, gimen dulcemente. Ya estoy de pie. (2015, p. 19). Qué callada la casa, sin ti, qué madre la casa, qué útero sombrío recordándote. Tu ausencia queda dibujada en un orden que es un desorden, y el flash de otros veranos fija en las paredes de tu brevísima biografía de osos, playas, disfraces, mares y desayunos. (2015, p. 71).

En las tres obras, los autores necesitan recorrer su vida completa, hacia atrás y hacia delante: detenerse, dejar la escritura, preguntarse por ella, desencontrarse con la vida y con los otros:

Te quedan tus maravillosos recuerdos, me decía la gente más tarde, como si los recuerdos trajeran consuelo. No lo traen. Los recuerdos son por definición del pasado, de lo que ya no está. Los recuerdos son los uniformes de la Westlake que hay en el armario, las fotografías descoloridas y agrietadas, las invitaciones a las bodas de gente que ya no está casada, las tarjetas impresas en serie de funerales de gente cuya cara ya no recuerdo. Los recuerdos son las cosas que ya no quieres recordar. (Didion, 2012, p. 55).

En otros momentos, encontrar en la escritura un espacio de desesperación:

La fiebre del hijo, el fuego en que me arde, la hoguera inexistente en que se quema, el abismo rojo donde le pierdo. La fiebre y el horror. Cómo se puede vivir en el horror. Se puede. La muerte en torno, la fiebre ondeando sus fatigadas banderas, el miedo. Pero se puede vivir -y esto es lo atroz- en la entraña misma del horror. También el horror puede llegar a ser de alguna manera confortable. Tener a un ser en la muerte es tenerlo ya seguro, a salvo, fijo, como una estrella, libre de todos los peligros, más allá de todas las riadas de la vida. (Umbral, 2015, p. 153).

[...] hay que beber a morro del dolor, como se bebe de las férreas fuentes. Que esta carne de luz empape toda la sombra. Hay que baldear hasta el fin el ciego enlagunamiento de la sangre. Hay que agotar el mal, el sufrimiento, no en pequeños sorbos, no en tragos cobardes, sino seguido y hasta lo hondo, que luego queda un fuego neutro, una nada, y sólo resta, por fin, la loza simple de la vida. (Umbral, 2015, p. 195).

O un lugar que les impida encontrarse desnudos ante el dolor descarnado:

Lo urgente es también este libro. Con su escritura esquivo lo importante. Encaro la pena con palabras, y mientras resuelvo problemas de estilo, depuro el lenguaje y estructuro sus páginas, evito ser tragado por lo importante. Cuidar de los detalles literarios es mi forma de asirme al mástil y mantenerme al mando de la nave. De otro modo, me perderían las sirenas o me cegaría la contemplación del brillante y amorfo espanto que me rodea y me atraviesa. (Del Molino, 2017, pp. 126-127).

Las tres obras muestran como la vida se convierte de repente en un relato en el que en ocasiones ya no están presentes:

Las advertencias caen en blando. Las escucho muy lejanas, como si se las dijeran a otro y yo fuera un espía apostado en la habitación de al lado. (Del Molino, 2017, p. 60). 
Qué pereza pues, incorporarse a ese mundo cínico y duro. La muerte y la enfermedad me han apartado de él con mano negra y leve. Qué pereza volver. Así que pido otro vaso de leche, abro el viejo libro por la página más conocida, paseo por la casa como un anciano de asilo, miro los restos del verano como un sobreviviente. (Umbral, 2015, p. 213).

O en espacios, fuera del espacio físico tangible, de encuentro con el otro perdido:

En las escaleras mecánicas de las tiendas dialogo con mi hijo muerto. Ante los quioscos de periódicos soy una página rasgada que se lleva el viento. La vida se ha quedado hueca de tiempo, el tiempo se ha quedado hueco de días. (Umbral, 2015, p. 223).

Este libro, hijo, que nació no sé cómo, que creció en torno a ti, sin saberlo, se ha convertido en el lugar secreto de nuestras citas, en el refugio solo de mi conversación, de mi monólogo contigo, aunque ya toda mi vida es ese monólogo y no hacemos otra cosa que conversar, tú y yo, sin que nadie nos oiga. (Umbral, 2015, p. 241).

La narración transcurre para dar presencia a lo ocurrido, para decirlo, para mantenerlo vivo porque es intolerable aceptar su ausencia. Otros textos más conocidos, como los de Primo Levy, Ruth Klüger, Liona Milu, intentan, a su vez, comprender cómo han podido pasar -y sobrevivir- no ya una pérdida personal, sino una atrocidad colectiva.

\subsection{DIBUJAR EL DOLOR}

El cómic ha utilizado también su especial tipo de narrativa como espacio autobiográfico para evocarnos la ausencia y el dolor. Obras como Maus, de Art Spigelman, Persepolis, de Marjane Satrapi, o en España, Paracuellos, de Carlos Jiménez, El arte de volar, de Antonio Altarriba, hablan de las vivencias del pasado desde una narrativa personal. Otras, como la de Alison Bechdel, Fun Home, una familia tragicómica (2006) o ¿Eres mi madre? (2012), dan prueba de la fuerza de este formato que permite acercarse desde lo ingenuo que provoca el cómic, a la narrativa más dura y descarnada. Maus, en palabras de Faxedas (2010):

[...] representa una de la reflexiones más profundas y lúcidas no sólo sobre el propio hecho del Holocausto, sino sobre la dificultad de vivir con este hecho como parte de la experiencia personal y familiar, no ya sólo a nivel físico, sino especialmente a nivel moral y espiritual, y de construir una vida propia en la que una experiencia como ésta no destruya todo aquello que de bueno haya podido aparecer después del horror. (2010, p. 132).

Las tres obras, en palabras Moreno y Nuño (2009) comparten varios elementos: su realización en blanco y negro; la memoria histórica, que aparece desvanecida en el tiempo a través del tratamiento formal; la coincidencia de partir de una narración autobiográfica, opuesta a lo que se suele entender por "héroes": en Paracuellos los personajes son niños; en Maus, los judíos son ratones; en Persépolis, Marji sufre la triple marginación de ser niña, mujer e iraní. Los tres comparten la representación del cuerpo como lugar de control, disciplina y terror.

El arte de volar forma parte también de este género: una novela gráfica realizada por el guionista Antonio Altarriba y el dibujante Kim. La obra narra la vida de Antonio Altarriba 
Estudios Pedagógicos XLIII, N 4: 147-160, 2017

ALETHEIA: CONTRA EL OLVIDO. ESTRATEGIAS A TRAVÉS DEL ARTE PARA ELABORAR LA MEMORIA

EMOCIONAL ¿QUÉ HACER CON EL PATRIMONIO INMATERIAL DEL RECUERDO TRAUMÁTICO?

Lope -padre del guionista-, desde su niñez hasta su suicidio, acaecido en 2001 como consecuencia de una intensa depresión:

Siempre he estado en él porque un padre está hecho de sus hijos posibles, y yo soy el único hijo que le fue posible a mi padre. Desciendo de mi padre, soy su prolongación y, cuando todavía no había nacido, ya participaba, como potencial genético, de todo lo que le ocurría. Por eso sé cómo murió, y también como vivió. Me contó muchas veces sus peripecias. Incluso, para paliar los primeros síntomas de la depresión, le insistî muchas veces en que las escribiera. Dejó doscientas cincuenta cartillas de letra apretada y rebosante de recuerdos. Pero lo que sé de él no es por haberlo oído o leído: lo que sé de su vida es porque, como he dicho, yo estaba con él, o quizá era con él, y ahora, una vez muerto, él está en mí. Así que puedo contar su vida con la verdad de sus testimonios y la emoción de una sangre que aún corre por mis venas. De hecho, voy a contar la vida de mi padre con sus ojos pero desde mi perspectiva. (Altarriba \& Kim, 2010, pp. 11-13).

El cómic se desvela como uno de los modos donde el arte, secuenciado y con posibilidad de armarse en una progresión cronológica, permite reorganizar fragmentos de una memoria emocional que han quedado desgajados de un análisis lógico y organizado.

\section{EL TRABAJO DE LA NARRACIÓN PERSONAL EN EDUCACIÓN Y TERAPIA: ¿PARA QUÉ CONTARNOS?}

La narración autobiográfica, confesional, permite comprendernos. De acuerdo con Bruner "la narración es la forma de pensamiento y expresión de la visión del mundo de una cultura" (1997, p. 15).

Siguiendo a Carr (1998), dentro del marco narrativo los problemas humanos surgen y se mantienen cuando son vistos como historias o narraciones opresivas que dominan la vida de una persona. Los problemas humanos surgen cuando el modo en que las personas relatan sus vidas a sí mismas y a los otros, no concuerda con su experiencia vivida (Carr, 1998). El enfoque narrativo descansa en la asunción de las narrativas no como representaciones o reflejo de las identidades, las vidas y los problemas, sino como constitutivas en sí mismas de identidades, vidas y problemas (Bruner, 1986, 1987, 1991). De acuerdo con esta posición, el proceso de volver a ser el "autor/a" de las narrativas personales puede ayudar a cambiar las vidas, la percepción de los problemas y las identidades, porque las narrativas personales son constitutivas de la identidad (Carr, 1998).

Desde hace décadas el enfoque narrativo ha sido un modo de indagar también en el conocimiento pedagógico, utilizando para ello diversos métodos e instrumentos. Ejemplo de ello es el caso del padre Manjón (1900) y la importancia que el fundador de las Escuelas del Ave María le concedía a la elaboración de diarios por parte de los profesores y los alumnos para recoger lo más relevante ocurrido en las escuelas (Mateos \& Núñez, 2011). Según estos autores, la narración "supone adentrarse no sólo en el terreno de lo que está aconteciendo desde estos escenarios, sino también en la dimensión subjetiva desde la que estos actores educativos dan sentido a la realidad" (Mateos \& Núñez, 2011, p. 114). Como señalan Connelly y Clandinin (1995), los humanos somos seres "contadores de historias", vivimos vidas insertas, o que deben insertarse en un relato a través del cual 
experimentamos el mundo. Así pues, y siguiendo a Mateos y Núñez (2011), la narrativa está directamente relacionada con la representación que construimos del mundo personal y social en diferentes modos y maneras:

- Como modo de ordenar la experiencia de vida y darle un significado: "A través de la narrativa, los seres humanos proyectan la interpretación de eventos, acciones, situaciones y confieren significado y sentido a la propia experiencia" (Mateos \& Núñez (2011, p. 121).

- Se implica en la forma de vivir el mundo y contiene el conocimiento práctico. Como señalan Colom y Mèlich (2003),

la relación entre la narración y la vida es doble. De un lado, la narración remite a la vida, ya que el proceso de creación y composición de la narración es llevado a cabo por el lector. En este sentido, leer es un modo de vivir, así como contar y leer narraciones es vivirlas en el mundo de lo imaginario. De otro, la vida misma remite a la narración en tanto que la vida además de ser desarrollo biológico es concreción de una biografía, historia o relato, cuyo texto puede interpretar y experimentar de distintos modos (2003, p. 121).

Los acontecimientos o acciones deben organizarse en tramas o argumentos de una historia narrativa con sentido y significado.

- Instrumento para transmitir la experiencia propia y ajena, actuando como mediador de la vinculación educación-cultura. Dentro de las culturas orales la narrativa desempeña un importante papel al constituir el principal instrumento intelectual y práctico de transmisión del conocimiento (Colom \& Mèlich, 2003).

A partir de esta premisa, la necesidad de contarnos, surgen también las narrativas emancipadoras, las "emancipatory narratives" (McEwan, 1997), relatos que se caracterizan por liberar nuestro pensamiento de la presión de la conformidad y el relato establecido, facilitando medios para expresar y crear nuevos significados que de este modo, se convierten en una re-estructura y permiten la relectura en otros términos.

Partiendo de esta postura, la narrativa permite la deconstrucción y la constitución, siguiendo a Derrida (1981). Una posición deconstruccionista permite activar la capacidad de los participantes de subvertir las definiciones, roles y constructos establecidos por la sociedad. Una postura constitucionalista permite, por otro lado, permitirse pensar que las vidas y las identidades están construidas a partir de los significados que las personas dan al relato de sus experiencias; del lenguaje que las personas eligen para expresarlo, unido al tipo de vocabulario que usan para contar sus vidas; y la situación o jerarquía que las personas ocupan en la estructura social en la que participan y las relaciones de poder que esta conlleva (Carr, 1998).

Reflexionar sobre estos tres factores -significado, lenguaje y posición de poder-ayuda a reconocer y deshacer subalteridades impuestas por los otros y que en un momento dado han podido producir aislamiento y dolor.

Del mismo modo, las técnicas usadas en terapias narrativas pueden ser muy útiles -en Educación y Terapia-, de acuerdo con White (1995) cuando:

- Adoptamos una posición consultiva de co-autoría colaborativa.

- Ayudamos a los clientes/pacientes/participantes a verse a sí mismos como 
separados de sus problemas externalizando el problema.

- Ayudamos a los clientes/pacientes/participantes a identificar los momentos en sus vidas cuando no oprimidos por sus problemas al encontrar resultados únicos.

- Reformando las descripciones de nuestros participantes en escenarios de acción y escenarios de conciencia.

- Vinculamos resultados únicos a otros eventos en el pasado y ayudamos a extender la historia en el futuro para formar una alternativa y preferimos una auto-narrativa en la que el yo es visto como más poderoso que el problema.

- Invitamos a miembros significativos de la red social de los participantes a compartir esta nueva auto-narrativa.

- Documentamos nuevos conocimientos y prácticas que apoyen la nueva autonarrativa usando medios literarios.

- Permitir que otros, atrapados también por narraciones opresivas similares, puedan beneficiarse de sus nuevos conocimientos a través de un feedback (Carr, 1998).

La narrativa moviliza aspectos que ayudan a mirarnos desde otras perspectivas, más allá de aquellas donde nos han colocado o nos hemos colocado de modo inconsciente. Ayuda a exteriorizar el caos y dolor interno, extraerlo, dándole forma a través del lenguaje -sea este escrito, dibujado, dramatizado, danzado-, a verlo fuera de nosotros mismos: organizándolo a través de líneas, colores, composición o estructura; a través de verbos, adverbios y determinados adjetivos; a través de ritmos, gestos y movimientos; a reflexionar por qué unos y no otros. A darles un nuevo significado. A que este significado conformado sea compartible. A comunicarlo a los otros.

Los procesos creadores son portadores de consciencia sobre lo inconsciente y ofrecen la capacidad de reprocesar el sufrimiento enquistado de forma, si no indolora, al menos con un grado menor de desbordamiento: la capacidad simbólica del arte permite sentir de nuevo en un espacio seguro, todo el dolor pasado. En él, gracias a la capacidad estructuradora del arte, podemos perdonarnos, comprendernos, revisitarnos y desde el aquí y ahora, aportar palabras de afecto a aquel yo que se derrumbó de dolor en el pasado.

\section{REFERENCIAS BIBLIOGRÁFICAS}

Ainsworth, M.D. (1989). Attachment beyond infancy. American Psychologist, 44, 709- 716.

Altarriba, A. (2010). El arte de volar. Alicante: Edicions de Ponent.

Balint, M. (2001). Amor primario y técnica psicoanalítica. París: Hachette.

Balint, M. (2006). La falta fundamental. París: Payot-poches.

Bechdel, A. (2006). Fun Home: A Family Tragicomic. London: Jonathan Cape, Random.

Bechdel, A. (2012). Are You My Mother? A Comic Drama. Houghton: Mifflin Harcourt.

Bower, H. (1999, April 13). The pen is mightier than the pill. The Guardian. Retrieved from www. theguardian.com/lifeandstyle/1999/apr/13/healthandwellbeing.health4

Bowlby, J. (1989). Una base segura: aplicaciones clínicas de una teoría del apego. Barcelona: Editorial Paidos.

Bruner, J. (1986). Actual minds- possible worlds. Cambridge, MA: Harvard University Press.

Bruner, J. (1987). Life as narrative. Social Research, 54, 12-32.

Bruner, J. (1991). The narrative construction of reality. Critical Inquiry, 18, 1-21.

Bruner, J. (1997). La educación, puerta de la cultura. Madrid: Visor.

Carr, A. (1998). Michael White's Narrative Therapy. Contemporary Family Therapy, 20(4), 485-503. 
Collie, K., Backos, A., Malchiodi, C. A., \& Spiegel, D. (2006). Art therapy for combat-related PTSD: Recommendations for research and practice. Art Therapy: Journal of the American Art Therapy Association, 23(4), 157-164.

Colom, A., \& Mèlich, J. (2003). Narratividad y educación. En Otros lenguajes en educación. Barcelona: ICE de la Universitat de Barcelona.

Connelly, M., \& Clandinin, J. (1995). Relatos de experiencia e investigación narrativa. En J. Larrosa, R. Arnaus, V. Ferrer, N. Pérez de Lara, M. Connelly, J. Clandinin y M. Greene, Déjame que te cuente. Ensayos sobre narrativa y educación (pp. 11-59). Barcelona: Laertes.

Christianson, S. A. (1992). The handbook of emotion and memory. Hillsdale, NJ: L. Erlbaum Associates.

Del Molino, S. (2017). La hora violeta. España: Literatura Random House:

Damasio, A. (1999). The Feeling of What Happens: Body and Emotion in the Making of Consciousness. New York: Harcourt Brace.

Derrida, J. (1981). Positions. Chicago: University of Chicago Press.

Didion, J. (2012). Noches azules. Madrid: Random House.

Faxedas, M. (2010). De ratones y hombres. Maus, de Art Spiegelman. Escritura e imagen 6, 129-145.

Francis, M. E., \& Pennebaker, J.W. (1992) Putting stress into words. Writing about personal upheavals and health. American Journal of Health Promotion, 6, 280-287.

Goldman, I. (2012). Theory of Mind. Handbook of Philosophy and Cognitive Science. Oxford: Oxford University Press.

Herman, J. (1992). Trauma and recovery. The Aftermath of Violence from Domestic Abuse to Political Terror. New York: Basic Books.

López Fernández-Cao, M. (2016), Curar las Heridas: la creación para evocar la ausencia. La memoria de la escritura. La memoria del cuerpo. Arteterapia, papeles de arteterapia y educación artística para la inclusión social, 11, 365-384

Lusebrink, B. (2004). Art Therapy and the brain. Art Therapy: Journal of the American Art Therapy Association, 21(3), 125-135.

Mateos, T., \& Núñez, L. (2011). Narrativa y educación: indagar la experiencia escolar a través de los relatos. Teoría de la educación, 23(2), 111-128.

McEwan, H. (1997). The functions of narrative and research on teaching. Teaching and Teacher Education, 13(1), 85-92.

Moreno-Nuño, C. (2009). The Comic-Strip Of Historical Memory: An Analysis Of Paracuellos By Carlos Giménez, In The Light Of Persépolis By Marjane Satrapi And Maus By Art Spiegelman. Vanderbilt e-Journal of Luso-Hispanic Studies, 5, 177-195.

Pennebaker, J.W. (1990). Opening Up: The Healing Powers of Confiding in Others. New York: William Morrow.

Pennebaker, J.W., \& Beall, S. (1986). Confronting a traumatic event: toward an understanding of inhibition and disease. Journal of Abnormal Psychology, 95, 274-281.

Rauch, S.L., \& Shin, L.M. (1997). Functional neuroimaging studies in posttraumatic stress disorder. Proceedings of the National Academy of Sciences, 821, 83-98.

Read Johnson, D. (1998). On the therapeutic action of the creative arts therapies: the psychodynamic model. The Arts in Pychotherapy 25(2), 85-99.

Riley, S. (2004). The Creative Mind. Art Therapy: Journal of the American Art Therapy Association, 21(4), 184-190.

Sadock, B., Sadock, V., \& Ruiz, P. (2002). Kaplan and Sadock's Comprehensive Textbook of Psychiatry. Philadelphia: Lippincott Williams \& Wilkins.

Stern, D. (1985). El mundo interpersonal del infante: Una perspectiva desde el psicoanálisis y la psicología evolutiva. Buenos Aires: Paidós.

Umbral, F. (2015). Mortal y Rosa. Madrid: Planeta.

Van der Kolk, B. (1994). The body keeps the score: Memory and the evolving psychobiology of post 
Estudios Pedagógicos XLIII, N 4: 147-160, 2017

ALETHEIA: CONTRA EL OLVIDO. ESTRATEGIAS A TRAVÉS DEL ARTE PARA ELABORAR LA MEMORIA

EMOCIONAL ¿QUÉ HACER CON EL PATRIMONIO INMATERIAL DEL RECUERDO TRAUMÁTICO?

traumatic stress. Harvard Review of Psychiatry, 1(5), 253-265.

Van der Kolk, B. (2015). El cuerpo lleva la cuenta. Cerebro, mente y cuerpo en la superación del trauma. Barcelona: Elephteria.

Van der Kolk, B., \& Fisler, R. (1995). Dissociation and fragmentary nature of traumatic memories: Onerview and exploratory study. Journal of Traumatic Stress, 15, 255-258.

Van der Kolk, B. A., Hostetler, A., Herron, N., \& Fisler, R. E. (1994). Trauma and the development of borderline personality disorder. Psychiatric Clinics of North America, 17(4), 715-730.

White, M. (1995). Re-authoring lives. Adelaide: Dulwich Centre Publications. 